University of Nebraska - Lincoln

DigitalCommons@University of Nebraska - Lincoln

2009

\title{
A Simplified Method for Extracting Androgens From Avian Egg Yolks
}

Corinne P. Kozlowski

University of Missouri - St Louis, kozlowski@stlzoo.org

Joan E. Bauman

Saint Louis Zoo

D. Caldwell Hahn

USGS, chahn@usgs.gov

Follow this and additional works at: https://digitalcommons.unl.edu/usgsstaffpub

Kozlowski, Corinne P.; Bauman, Joan E.; and Hahn, D. Caldwell, "A Simplified Method for Extracting Androgens From Avian Egg Yolks" (2009). USGS Staff -- Published Research. 604.

https://digitalcommons.unl.edu/usgsstaffpub/604

This Article is brought to you for free and open access by the US Geological Survey at DigitalCommons@University of Nebraska - Lincoln. It has been accepted for inclusion in USGS Staff -- Published Research by an authorized administrator of DigitalCommons@University of Nebraska - Lincoln. 


\title{
TECHNICAL REPORT
}

\section{A Simplified Method for Extracting Androgens From Avian Egg Yolks}

\author{
Corinne P. Kozlowski, ${ }^{1,2 *}$ Joan E. Bauman, ${ }^{1}$ and D. Caldwell Hahn ${ }^{3}$ \\ ${ }^{1}$ Research Department, Saint Louis Zoo, St. Louis, MO \\ ${ }^{2}$ Department of Biology, University of Missouri-St. Louis, St. Louis, MO \\ ${ }^{3}$ USGS-Patuxent Wildlife Research Center, Laurel, MD
}

\begin{abstract}
Female birds deposit significant amounts of steroid hormones into the yolks of their eggs. Studies have demonstrated that these hormones, particularly androgens, affect nestling growth and development. In order to measure androgen concentrations in avian egg yolks, most authors follow the extraction methods outlined by Schwabl (1993. Proc. Nat. Acad. Sci. USA 90:11446-11450). We describe a simplified method for extracting androgens from avian egg yolks. Our method, which has been validated through recovery and linearity experiments, consists of a single ethanol precipitation that produces substantially higher recoveries than those reported by Schwabl (1993. Proc. Nat. Acad. Sci. USA 90:11446-11450). Zoo Biol 28:137-143, 2009. $\quad$ (C) 2008 Wiley-Liss, Inc.
\end{abstract}

Keywords: testosterone; androstenedione; extraction; avian yolk; radioimmunoassay

\section{INTRODUCTION}

The mechanisms that parents use to improve offspring fitness is central to the study of adaptive maternal effects [Mousseau and Fox, 1998]. Birds are an ideal system for investigating these effects because their eggs contain a number of resources that are important for embryonic development. Steroid hormones in egg yolk organize phenotypic differentiation and regulate physiological functions [Groothuis et al., 2005]. Several steroid hormones have been identified in avian egg yolk: testosterone, $5 \alpha$-dihydrotestosterone, androstenedione, and estradiol [Schwabl, 1993]; progesterone [Lipar et al., 1999]; corticosterone [Saino et al., 2005]. Of these, two

*Correspondence to: Corinne P. Kozlowski, Research Department, Saint Louis Zoo, 1 Government Drive, St. Louis, Missouri 63110. E-mail: kozlowski@stlzoo.org

Received 7 December 2007; Accepted 30 April 2008

DOI 10.1002/zoo.20221

Published online 17 November 2008 in Wiley InterScience (www.interscience.wiley.com).

(C) 2008 Wiley-Liss, Inc.

This article is a U.S. government work, and is not subject to copyright in the United States. 
androgens, testosterone and androstenedione, have been most widely researched because of their effects on nestling growth and development.

Differential deposition of androgens into egg yolk provides females with a means to adaptively modify offspring phenotype. Exposure to high androgen levels during embryonic development may shorten incubation period [Eising et al., 2001], and increase begging vigor [Schwabl, 1996], growth [Navara et al., 2005], and survival [Pilz et al., 2004] in different species. Variation in the amount of androgens deposited into yolks occurs both within and between clutches. Within-clutch variation is believed to regulate sibling competition in species that produce asynchronously hatching clutches. Females can either increase [Lipar et al., 1999] or decrease yolk androgen levels [Schwabl et al., 1997] with egg lay order to counteract or reinforce the formation of a size hierarchy within the brood. Variation in androgen allocation among females has been attributed to environmental factors. Females that lay eggs containing higher levels of yolk androgens, may be experiencing social stress [Mazuc et al., 2003], have mated with a more attractive male [Gil et al., 1999], or are in poor health [Verboven et al., 2003].

The concentration of androgens in avian yolk is most frequently assessed using radioimmunoassays, which are readily available, inexpensive, and extremely sensitive. Because androgens cannot be measured directly in the yolk, extraction is necessary to remove substances such as lipids and proteins that can bind to hormones or interfere with the binding of the hormone to the antibody. There is no standard method for extracting androgens from avian yolk. Most authors, however, follow the extraction protocol published by Schwabl [1993]. The efficiency of this method, assessed by adding a known amount of hormone to the yolk sample and then measuring the amount recovered after extraction, was found by Schwabl [1993] to be $59 \%$ for testosterone and $53 \%$ for androstenedione. Other investigators use different methods of extraction that have recoveries ranging from 49 to $85 \%$ [see von Engelhardt and Groothuis, 2005].

We describe a simplified method for extracting androgens, testosterone (T) and androstenedione (A4), from avian egg yolks. The procedure consists of a simple ethanol precipitation using a single extraction, so as to reduce loss of hormone from experimenter error. In serum samples, ethanol is commonly used to remove proteins and extract steroids and other nonprotein hormones [Chopra et al., 1992]. We have assessed the efficiency of our extraction through parallelism and recovery experiments, and compared it with the protocol outlined by Schwabl [1993]. Our procedure produces recoveries substantially higher than those obtained by Schwabl [1993].

\section{METHODS}

\section{Preparation of Samples}

This procedure was performed on eggs collected from a captive colony of Eastern screech owls (Megascops asio) at USGS-Patuxent Wildlife Research Center in Laurel, MD. All owl eggs used in this study were unincubated and had been removed from the nest within $24 \mathrm{hr}$ of laying. Immediately after collection, all eggs were frozen at $-70^{\circ} \mathrm{C}$.

To prepare yolks for hormone analysis, the frozen yolk was first separated from the albumin and weighed. Frozen yolks were then transferred to plastic $50 \mathrm{~mL}$ conical tubes and allowed to thaw at room temperature for $1 \mathrm{hr}$. Yolks were next 
diluted with phosphate-buffered saline (PBS). One milliliter of PBS was added per gram of yolk. Several glass mixing beads were added to the yolk. The yolk solution was vortexed for $5 \mathrm{~min}$, and the sample was frozen at $-70^{\circ} \mathrm{C}$ until extraction.

\section{Extraction Procedure}

In preparation for extraction, yolk solutions were thawed and homogenized with a vortex for $1 \mathrm{~min}$. Next, $100 \mu \mathrm{L}$ of yolk was transferred into a $2 \mathrm{~mL}$ eppendorf tube. Yolk samples ranged in weight from 0.16 to $0.44 \mathrm{~g}$ (mean $=0.23 \mathrm{~g}, n=30)$. Because hormone concentrations are expressed as nanograms per gram of yolk, variation in the sample masses do not contribute to error in the measurement of hormone concentrations. Then, $400 \mu \mathrm{L}$ of PBS was added to further dilute the yolk; the sample was then homogenized and incubated at $37^{\circ} \mathrm{C}$ for $1 \mathrm{hr}$.

After incubation, $500 \mu \mathrm{L}$ of $100 \%$ ethanol was added to each sample. Upon adding ethanol, the samples were immediately homogenized for 1 min using a vortex, and allowed to incubate at room temperate for $10 \mathrm{~min}$. Samples were then spun at $13,000 \mathrm{rpm}$ in a micro-centrifuge for $10 \mathrm{~min}$. The supernatant was poured into a sterile cryotube and frozen at $-70^{\circ} \mathrm{C}$ until an assay was performed.

\section{Radioimmunoassay}

In preparation for assay, ethanol extracts were thawed and spun in a centrifuge at $4,000 \mathrm{rpm}$ for $10 \mathrm{~min}$ to remove any remaining lipids. Hormone concentrations were measured using commercially available coated-tube radioimmunoassay kits (Coat-A-Count (C) Testosterone 125I Kit, and Coat-A-Count (C) Direct Androstenedione 125I Kit, Diagnostic Products Corporation, Los Angeles, CA). These kits have highly specific antibodies and a low cross-reactivity with other androgens. In our testosterone assay, lower detection limits were $0.05 \mathrm{ng} / \mathrm{mL}$ and upper limits were $40 \mathrm{ng} / \mathrm{mL}$. Lower detection levels of the androstenedione assay were $0.11 \mathrm{ng} / \mathrm{mL}$, and upper detection limits were $8.7 \mathrm{ng} / \mathrm{mL}$.

Assays were run according to kit directions, with the exception that the kit standards, which are supplied in human serum, were replaced by standards diluted in $10 \%$ steroid free calf serum. This was added to the standard diluent to reduce nonspecific binding. In order to equalize the matrices of standards and samples, $10 \%$ steroid free calf serum was added to yolk extract samples, and steroid-stripped pooled yolk extract was added to standards and quality controls. Calf serum and pooled egg yolk extract were stripped of steroids using dextran-coated charcoal (DCC \# 6241, Sigma Chemical, St. Louis MO) before use.

In total, T and A4 were measured in 30 eggs. All samples were run in duplicate. A total of three $\mathrm{T}$ assays and one A4 assay were conducted. Mean \pm SEM intra-assay variation of duplicate samples was $3.36 \pm 0.24$ for $\mathrm{T}$ and $6.57 \pm 1.75$ for $\mathrm{A} 4$. Inter-assay variation of quality controls was $1.38,8.59$, and $0.73 \%$ for low, medium, and high $\mathrm{T}$ controls.

\section{Validation of Extraction Technique}

\section{Extraction efficiency}

To determine extraction efficiency of both testosterone and androstenedione, we added a known amount of radioactively labeled hormone to the yolk sample before extraction, and measured the amount of radioactivity after the extraction process. In ten experimental samples each for $\mathrm{T}$ and A4, $100 \mu \mathrm{L}$ of I-125 labeled 
hormone was added to $100 \mu \mathrm{L}$ of yolk and $300 \mu \mathrm{L}$ of PBS. In control samples, $100 \mu \mathrm{L}$ of labeled hormone was added to $400 \mu \mathrm{L}$ of PBS. In order to measure the total radioactivity present in the sample, two samples of $100 \mu \mathrm{L}$ of labeled hormone were set aside. Yolk and control samples were then extracted as described above, and $500 \mu \mathrm{L}$ of supernatant was transferred from each sample to an individual $12 \times 75$ plastic test tube. The total amount of radioactivity in each sample was then measured in both yolk and control samples, and compared with the total count tubes in order to determine the recovery percentage in each sample.

\section{Recovery}

In order to verify that our extraction procedure removed all substances that would interfere with binding between the hormone and the antibody in the coated tubes, we tested assayable recovery of known amounts of T and A4. Yolk extracts were prepared as described above, and then a known amount of hormone was added to yolk extracts containing low values of either $\mathrm{T}$ or A4. This procedure was performed at three different dosage levels for both T and A4. Yolk samples without exogenous hormone were also measured to determine the amount of endogenous hormone in the sample. This experiment was repeated for eight samples from four eggs laid by four different females, and eggs were chosen randomly with respect to laying order.

\section{Validation of Radioimmunoassay}

Cross-reacting substances seldom react with the same binding constants as the antigen against which the antibody was designed. Tests of parallelism, which ensure that the assay maintains linearity under dilution, are taken as evidence that the substance being measured is actually the hormone of interest. Eight samples (four for $\mathrm{T}$ and four for A4) that contained high levels of hormone were diluted by 1:2, 1:4, and 1:8 with stripped yolk extract. These dilutions, as well as the full strength sample, were measured using the RIA procedure described above.

\section{RESULTS}

Both testosterone and androstenedione were successfully detected in the screech owl egg yolk. Testosterone concentrations of 30 eggs averaged $36.64 \pm 2.80 \mathrm{ng} / \mathrm{g}$ and ranged from 11.46 to $76.06 \mathrm{ng} / \mathrm{g}$. Androstenedione concentrations averaged $26.88 \pm 2.14 \mathrm{ng} / \mathrm{g}$ and ranged from 9.73 to $62.43 \mathrm{ng} / \mathrm{g}$. Our first set of recovery experiments demonstrated that the technique described here is sufficient to extract both testosterone and androstendione from screech owl yolk samples (Table 1). Recovery ranged from 91 to $101 \%$ for both hormones, and did not differ between control and yolk samples (T: $t=-0.326$, df $=18, P=0.75$; A4: $t=-1.390$, $\mathrm{df}=18, P=0.18$ ). Our second recovery experiment established that our method of precipitation removes any material that would interfere with the accuracy of the testosterone assay (Table 2). Recovery of exogenous testosterone and androstenedione did not differ between dosage levels (T: $F_{2,11}=0.48, P=0.63$; A4: $F_{2,11}=0.93$, $P=0.43$ ).

Serial dilutions of screech owl samples measured an average of $91.22 \pm 2.21 \%$ of expected values for testosterone and $102.45 \pm 2.92 \%$ of expected values for androstenedione, and were all parallel to the standard curve (test of equal slopes, 
TABLE 1. Quantitative recovery of I-125 labeled testosterone and androstenedione in samples containing either screech owl yolk or PBS (control)

\begin{tabular}{lccc}
\hline & $N$ & Testosterone recovery & Androstenedione recovery \\
\cline { 2 - 4 } Sample & & $($ Mean $\% \pm$ SE) & $($ Mean $\% \pm$ SE) \\
\hline Control & 10 & $92.5 \pm 0.4$ & $93.0 \pm 0.6$ \\
Yolk & 10 & $92.7 \pm 0.5$ & $94.5 \pm 0.8$ \\
\hline
\end{tabular}

TABLE 2. Quantitative recovery of exogenous testosterone and androstenedione (including intra-assay coefficients of variation) for yolk extracts. Three levels of exogenous hormone were added to four yolk samples

\begin{tabular}{lccc}
\hline & $N$ & Quantitative recovery & Intra-assay CV \\
\cline { 2 - 4 } Exogenous hormone added & & $($ Mean $\% \pm \mathrm{SE})$ & (Mean $\% \pm \mathrm{SE})$ \\
\hline $\begin{array}{l}\text { Testosterone }(\mathrm{ng} / \mathrm{mL}) \\
0.49\end{array}$ & 4 & $98.0 \pm 2.3$ & \\
1.48 & 4 & $90.1 \pm 5.1$ & $5.1 \pm 3.0$ \\
4.44 & 4 & $108.8 \pm 5.6$ & $5.3 \pm 1.3$ \\
Androstenedione $(\mathrm{ng} / \mathrm{mL})$ & 4 & $93.5 \pm 6.5$ & $3.9 \pm 1.4$ \\
0.32 & 4 & $86.1 \pm 4.5$ & $7.4 \pm 2.8$ \\
0.97 & 4 & $93.7 \pm 4.3$ & $4.3 \pm 1.7$ \\
2.9 & & & $1.0 \pm 0.3$ \\
\hline
\end{tabular}

$P>0.10)$ [Zar, 1996]. This suggests that no additional substances in the extract were cross-reacting with the antibody (Fig. 1).

\section{DISCUSSION}

These results suggest that our procedure is effective for extracting two androgens, testosterone, and androstenedione, from the yolks of screech owl eggs. In addition, the performance characteristics of the radioimmunoassay (recovery of exogenous hormone, intra- and inter-assay variation, and parallelism) verify that it is accurate, precise, demonstrates linearity under dilution, and has the appropriate range of sensitivity.

The method we have developed is simpler and takes less time than previously described methods. Many authors follow the procedure outlined by Schwabl [1993], which involves extracting samples twice with a combination of ethers and drying under a stream of nitrogen. The extracts are then dissolved in $90 \%$ ethanol, frozen, and then washed with hexane. Celite chromatography is used to further remove excess lipids. This process produces recoveries of less than $60 \%$ for both testosterone and androstenedione. In contrast, our extraction procedure produces recoveries higher than $86 \%$ for both testosterone and androstenedione.

Although pooling different inter-specific hormone data from different labs is common in comparative analyses [Gorman and Williams, 2005; Goymann et al., 2004; Ketterson et al., 2005], this procedure assumes repeatability among the labs. Recovery 

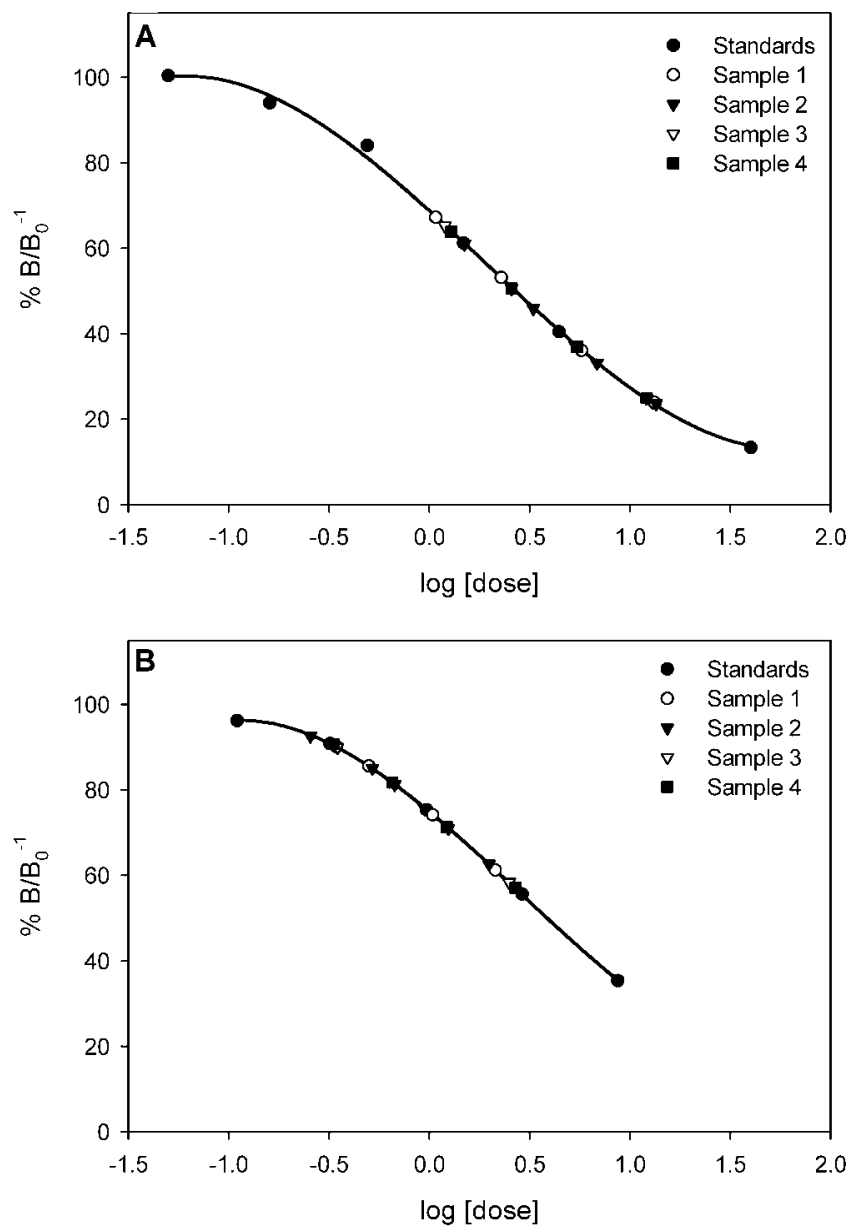

Fig. 1. Parallelism results for (A) testosterone and (B) androstenedione. Standard curves of percent binding of I-125 labeled hormone $\left(\% B B_{0}^{-1}\right)$ vs. four serially diluted samples (logtransformed doses of 1:2,1:4, and 1:8). All samples were parallel to testosterone and androstenendione standard curves (log-transformed doses of $0.5,0.16,0.49,1.48,4.44,13.3$, and $40 \mathrm{ng} / \mathrm{mL}(\mathrm{T})$ and $0.11,0.32,0.97$, and $8.7 \mathrm{ng} / \mathrm{mL}(\mathrm{A} 4))$.

rates often differ among extraction procedures, making comparative studies difficult. We suggest that the methods described here be used for examining yolk androgen concentrations in place of other published methods. Standardization will allow for accurate comparisons of yolk androgen concentrations among species, and facilitate a broader understanding of the evolutionary significance of yolk androgens.

\section{CONCLUSIONS}

(1) We have developed a method of extracting steroids from avian yolks using a single ethanol precipitation. 
(2) This method is simpler to perform and produces higher recoveries than the previously described method by Schwabl [1993].

\section{ACKNOWLEDGMENTS}

We thank Wayne Bauer and Melody Nevins for assistance with the owl colony and Graham W. Smith for providing research support funds.

\section{REFERENCES}

Chopra IJ, Wu SY, Teco GN, Santini F. 1992. A radioimmunoassay for measurement of $3,5,3^{\prime}$ triiodothyronine sulfate: studies on thyroidal and non thyroidal diseases, pregnancy, and neonatal life. J Clin Endocrinol Metab 75:189-194.

Eising CM, Eikenaar C, Schwabl H, Groothuis TGG. 2001. Maternal androgens in black-headed gull (Larus ridibundus) eggs: consequences for chick development. Proc R Soc Lond B 268:839-846.

Gil D, Graves J, Hazon N, Wells A. 1999. Male attractiveness and differential testosterone in zebra finch eggs. Science 286:126-128.

Gorman KB, Williams TD. 2005. Correlated evolution of maternally derived yolk testosterone and early developmental traits in passerine birds. Biol Lett-UK 1:461-464.

Goymann W, Moore IT, Scheuerlein A, Hirschenhauser K, Grafen A, Wingfield JC. 2004. Testosterone in tropical birds: effects of environment and social factors. Am Nat 164:327-334.

Groothuis TGG, Müller W, von Engelhardt N, Carere C, Eising C. 2005. Maternal hormones as a tool to adjust offspring phenotype in avian species. Neurosci Biobehav Rev 29:329-352.

Ketterson ED, Nolan V, Sandell M. 2005. Testosterone in females: mediators of adaptive traits, constraint on sexual dimorphism, or both? Am Nat 166:S85-S98.

Lipar JL, Ketterson ED, Nolan V, Casto JM. 1999. Egg yolk layers vary in the concentration of steroid hormones in two avian species. Gen Comp Endocrinol 115:220-227.

Mazuc J, Bonneaud C, Chastel O, Sorci G. 2003. Social environment affects female and egg testosterone in the house sparrow (Passer domsticus). Ecol Lett 6:1084-1090.
Mousseau TA, Fox CW. 1998. The adaptive significance of maternal effects. Trends Ecol Evol 13:404-407.

Navara KJ, Hill GE, Mendonca MT. 2005. Variable effects of yolk androgens on growth, survival, and immunity in Eastern bluebird nestlings. Physiol Biochem Zool 78:570-578.

Pilz KM, Quiroga M, Schwabl H, Adkins-Regan E. 2004. European starling chicks benefit from high yolk testosterone levels during a drought year. Horm Behav 46:179-192.

Saino N, Romano M, Ferrari RP, Martinelli R, Møller AP. 2005. Stressed mothers lay eggs with high corticosterone levels which produce low-quality offspring. J Exp Zool 303:998-1006.

Schwabl H. 1993. Yolk is a source of maternal testosterone for developing birds. Proc Natl Acad Sci USA 90:11446-11450.

Schwabl H. 1996. Maternal testosterone in the egg enhances postnatal growth. Comp Biochem Physiol 114:271-276.

Schwabl H, Mock D, Gieg J. 1997. A hormonal mechanism for parental favouritism. Nature 386:231.

Verboven N, Monaghan P, Evans DM, Schwabl H, Evans N, Whitelaw C. 2003. Maternal condition, yolk androgens and offspring performance: a supplemental feeding experiment in the lesser black-backed gull (Larus fuscus). Proc R Soc Lond B 270:2223-2232.

von Engelhardt N, Groothuis TGG. 2005. Measuring steroid hormones in avian eggs. Ann N Y Acad Sci 1046:181-192.

Zar JH. 1996. Biostatistical analysis, 4th ed. Upper Saddle River, NJ: Prentice-Hall. p 663. 